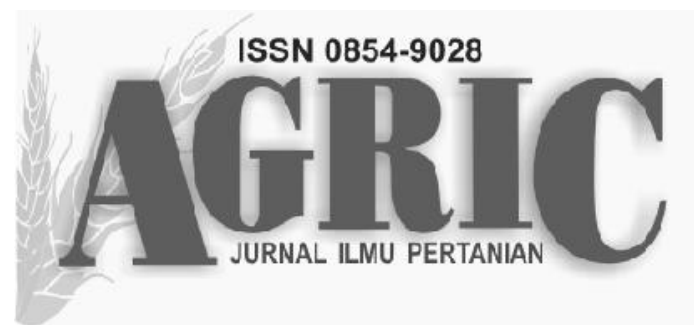

Fakultas Pertanian dan Bisnis Universitas Kristen Satya Wacana Jl. Diponegoro 52-60 SALATIGA 50711 - Telp. 0298-321212 ext 354 email: agric_fpb@yahoo.co.id, website: ejournal.uksw.edu/agric

\title{
PENGHAMBATAN PEMASAKAN BUAH SRIKAYA (Annona squamosa L.) DENGAN SUHU RENDAH DAN PELAPISAN KITOSAN
}

\section{RIPENING INHIBITION OF SUGAR-APPLE FRUIT (Annona squamosa L.) WITH LOW TEMPERATURE AND CHITOSAN COATING}

\author{
Widya Mudyantini \\ Jurusan Biologi FMIPA Universitas Negeri Sebelas Maret \\ Jl. Ir. Sutami Surakarta \\ Endang Anggarwulan \\ Jurusan Biologi FMIPA Universitas Negeri Sebelas Maret \\ Jl. Ir. Sutami Surakarta \\ Puji Rahayu \\ Jurusan Biologi FMIPA Universitas Negeri Sebelas Maret \\ J1. Ir. Sutami Surakarta
}

Diterima 25 Juni 2015, disetujui 10 Agustus 2015

\begin{abstract}
Annona squamosa L.is one of the perishable climateric fruit. The aims of this research were to study the ethylene levels, physiological and biochemical characters with application of temperatures and chitosan during storage. The research had been performed using Completely Randomized Design (CRD) with two factors, the variations in storage temperature $\left(5^{\circ} \mathrm{C}, 15^{\circ} \mathrm{C}, 25^{\circ} \mathrm{C}\right)$ and the variation in chitosan $(0 \%, 2 \%, 3 \%, 4 \%)$ with five replicates. The treatment of temperature $25^{\circ} \mathrm{C}$ and chitosan $0 \%$ was used as controls. The parameters observed included in respiration rate, weight loss, levels of ethylene, pigments, fruit hardness, ascorbic acid content and sugar reduction. Sugarapple fruit were taken from the same tree. The fruit were coated by chitosan and were stored at storage temperature. Observations were made in everyday until the controls were ripe. Data collected were analyzed using Anava followed byDMRTat 5\% test level. The result showed that the combination of storage temperatures and chitosanconcentrationshadsignificant effect on the shelf life and quality of sugar-apple fruit measured by several parameters. The treatments wereable to decrease weightloss and respiration rate, to maintain the content of water, the levels of sugar reduction, ascorbic acid content, the levels of a chlorophylls, $b$ chlorophylls, total chlorophylls, and carotenoids were remained still high. The higher temperature is the lower the ethylene levels. The best combination treatment to extend the shelf life and to maintain quality of sugar-apple fruit was chitosan $3 \%$ at temperatures $15^{\circ} \mathrm{C}$.
\end{abstract}

Keywords: Annona squamosa L., temperature, chitosan, fruit ripening 


\section{PENDAHULUAN}

Salah satu buah tropis yang cepat busuk adalah srikaya (Anona squamosa L.). Buah srikaya berbentuk bulat dengan kulit bermata banyak. Daging buahnya berwarna putih. Buah srikaya mempunyai masa simpan yang pendek, pada suhu ruang mulai matang sampai busuk tidak lebih dari seminggu. Buah srikaya termasuk buah klimaterik, sehingga laju respirasi dan produksi etilennya tinggi selama pemasakan. Struktur kulit yang mempunyai banyak mata dan pecah-pecah menyebabkan gas dan uap air mudah keluar masuk.

Memperlama masa simpan dapat dilakukan dengan menghambat laju respirasi dan produksi etilen. Pendinginan adalah perlakuan yang selama ini paling efektif menurunkan laju respirasi. Aktifitas metabolisme dan enzim akan menurun pada suhu rendah. Suhu rendah juga akan menghambat produksi etilen. Pelapisan pada buah dapat memberikan kekuatan mekanik pada kulit dan menahan gas masuk atau keluar serta mengurangi transpirasi buah. Bahan yang dipakai untuk pelapis harus aman dikonsumsi manusia. Salah satu bahan yang aman dan sudah banyak dipakai antara lain adalah kitosan. Keunggulan kitosan selain aman dikonsumsi karena berasal dari cangkang hewan laut juga mampu membentuk film yang kuat, elastis, fleksibel, menghambat pertumbuhan mikroba dan sulit dirobek. Potensi Indonesia sebagai sebagai negara kelautan sangat besar untuk menghasilkan kitosan. Proses pembuatannyapun tidak sulit dan murah.

Tujuan penelitian ini adalah menentukan pengaruh suhu rendah dan pelapisan kitosan terhadap pemasakan buah srikaya selama penyimpanan. Selain itu menentukan variasi perlakuan suhu rendah dan pelapisan kitosan yang paling lama memperpanjang masa simpan buah srikaya dan mengkaji mekanisme pemasakan secara fisiologis dan biokimiawi buah srikaya dengan perlakuan suhu rendah dan pelapisan kitosan selama penyimpanan.

\section{METODE PENELITIAN}

\section{Waktu dan Tempat Penelitian}

Penelitian ini dilaksanakan bulan Juni - Oktober 2014. Penelitian dilaksanakan di Laboratorium
Biologi dan Sub Laboratorium Biologi UPT Laboratorium Pusat Fakultas Matematika dan Ilmu Pengetahuan Alam, Universitas Sebelas Maret Surakarta serta di Lab. Biokimia Fakultas Teknologi Pertanian UGM.

\section{Alat dan Bahan}

Alat yang digunakan dalam penelitian ini antara lain: spektrofotometer Lamda 25 Perkin Elmer, kromatografi gas Shimadzu seri GC - 9AM kolom alumina, oksigen meter Lutron DO 5510, $\mathrm{CO}_{2}$ meter Lutron 2028, penetrometer Electric BI-235, oven, refrigerator, timbangan Mettler Toledo, cawan porselin, mortar. Bahan yang digunakan: kitosan, buah srikaya, asam asetat $1 \%$, asam ascorbat, garam rocella, reagensia arsenomolybdat, akuades, $\mathrm{Pb}$ asetat, indikator pati untuk uji total asam, larutan $\mathrm{NaOH} 0,1 \mathrm{~N}$, indikator PP, dan aseton $80 \%$, reagen untuk analisis lemak, kadar nutrisi.

\section{Cara Kerja}

Penelitian ini bersifat eksperimen dengan menggunakan metode Rancangan Acak Lengkap (RAL) pola faktorial yang terdiri atas dua faktor yaitu konsentrasi kitosan yang terdiri dari empat taraf dan suhu penyimpanan yang terdiri dari tiga taraf, sehingga akan diperoleh 12 kombinasi perlakuan. Setiap perlakuan dengan lima ulangan. Faktor konsentrasi kitosan dengan empat taraf, yaitu $0 \%, 2 \%, 3 \%$ dan $4 \%$. Faktor suhu penyimpanan dengan dua taraf, yaitu suhu $25^{\circ} \mathrm{C}, 15^{\circ} \mathrm{C}$ dan $5{ }^{\circ} \mathrm{C}$. Berdasarkan perlakuan tersebut diperoleh 12 kombinasi perlakuan.

1. Pelaksanaan Penelitian

a. Persiapan Buah Srikaya

Persiapan buah srikaya meliputi pemanenan, sortasi (pemilihan), pencucian, dan pengeringan. Buah srikaya dipanen dari lahan atau kebun di wilayah Pati. Sortasi atau pemilihan dilakukan dengan cara memilih buah srikaya dengan kriteria tingkat kematangan yang sama, ukuran buah yang sama $(170 \mathrm{~g})$, dan bebas dari penyakit. Buah diambil dari pohon yang sama. Pencucian dilakukan dengan meletakkan buah srikaya pada ember besar dengan air mengalir agar kotoran yang menempel pada kulit buah hilang. Setelah proses pencucian selesai, buah dikeringanginkan di dalam ruangan. 
b. Pembuatan Pelapis Buah dari Kitosan

Pelapis buah dari kitosan dibuat dengan konsentrasi $2 \%, 3 \%$ dan $4 \%$ dengan melarutkan kitosan dalam asam asetat $1 \%$. Larutan disimpan pada suhu kamar.

\section{c. Proses Pelapisan pada Buah}

Buah srikaya dicelupkan ke dalam bak pencelupan berisi larutan kitosan dengan konsentrasi $0 \%$ (kontrol), 2\%, 3\%, dan 4\% selama 10 menit.

\section{d. Penyimpanan Buah Srikaya}

Buah srikaya disimpan pada suhu $25^{\circ} \mathrm{C}$ (kontrol) dan suhu dingin $\left(5^{\circ} \mathrm{C}, 15^{\circ} \mathrm{C}\right)$ untuk selanjutnya diamati berbagai parameter fisiologis dan biokimianya setiap hari sampai buah busuk.

\section{e. Parameter pengamatan}

Parameter yang diamati adalah susut bobot, vitamin C dengan spektrofotometer, tekstur diukur dengan alat penetrometer Electric BI-235, kandungan klorofil dan karotenoid diukur dengan spektrofotometer dan kadar etilen dengan GC.

\section{Analisis Data}

Data dianalisis menggunakan Analisis Varian (ANAVA) kemudian dilanjutkan dengan uji Duncan's Multiple Range Test (DMRT) pada taraf uji 5\% untuk mengetahui beda nyata antar perlakuan.

\section{HASIL DAN PEMBAHASAN}

Adapun data yang diperoleh adalah sebagai berikut:

1. Bobot basah

Data bobot basah dapat dilihat pada tabel 1 berikut,

Tabel 1. Bobot basah buah srikaya pada variasi konsentrasi kitosan dan suhu penyimpanan setelah 4 hari $(\mathrm{g})$.

\begin{tabular}{cccc}
\hline Sitosan & $5^{0} \mathrm{C}$ & $15^{0} \mathrm{C}$ & $25^{0} \mathrm{C}$ \\
\hline $0 \%$ & $143,2^{\mathrm{d}}$ & $129,0^{\mathrm{c}}$ & $86,8^{\mathrm{a}}$ \\
$2 \%$ & $150,9^{\text {de }}$ & $147,1^{\mathrm{de}}$ & $98,2^{\mathrm{b}}$ \\
$3 \%$ & $155,2^{\text {ef }}$ & $162,2^{\mathrm{f}}$ & $80,1^{\mathrm{a}}$ \\
$4 \%$ & $153,3^{\text {ef }}$ & $133,2^{\mathrm{c}}$ & $118,1^{\mathrm{c}}$ \\
\hline
\end{tabular}

Di awal penelitian sebelum buah diberi perlakuan, rata-rata berat buah adalah $170 \mathrm{~g}$. Hasil penelitian menunjukkan bahwa terjadi penurunan bobot basah srikaya selama penyimpanan. Penurunan terbesar terjadi pada suhu $25^{\circ} \mathrm{C}$. Pemberian suhu rendah mampu mempertahankan bobot basah srikaya. Suhu $5^{\circ} \mathrm{C}$ lebih baik dibandingkan suhu $15^{\circ} \mathrm{C}$, tetapi perlakuan suhu $15^{\circ} \mathrm{C}$ dan kitosan $3 \%$ paling baik mempertahankan bobot basah srikaya.

Penurunan bobot yang kecil sangat diharapkan dalam memperlama masa simpan buah. Penurunan susut bobot ini erat hubungannya dengan kandungan air dan perubahan cadangan makanan pada daging. Jaringan buah tetap hidup setelah pemanenan dan tetap mengalami proses respirasi serta kehilangan air (Burdon, 1997). Wills et al. (1981) menyatakan bahwa pengurangan berat pada bahan hasil pertanian terutama buah-buahan mempunyai korelasi positif dengan jumlah $\mathrm{CO}_{2}$ dan air yang dilepaskan. Hal ini merupakan penyebab kehilangan air secara langsung. Pengaruh lebih nyata akibat kehilangan air adalah perubahan pada rupa (penampakan), kelayuan atau pengkerutan pada buah. Kehilangan berat pada buah diakibatkan pula oleh proses respirasi dan transpirasi pada buah tersebut.

2. Kandungan klorofil dan katotenoid (pigmen kulit buah)

Perlakuan suhu rendah dan pelapisan kitosan mampu mempertahankan warna buah srikaya tetap hijau. Semakin tinggi suhu, warna kulit buah semakin kuning. Data klorofil dapat dilihat pada Tabel 2 di bawah ini,

Tabel 2. Klorofil total kulit buah srikaya pada variasi konsentrasi kitosan dan penyimpanan suhu $(\mathrm{mg} / \mathrm{l})$.

\begin{tabular}{cccc}
\hline Kitosan & $5{ }^{\circ} \mathrm{C}$ & $15^{\circ} \mathrm{C}$ & $25^{\circ} \mathrm{C}$ \\
\hline $0 \%$ & $4,74^{\text {abc }}$ & $8,18^{\text {de }}$ & $2,76^{\mathrm{a}}$ \\
$2 \%$ & $8,92^{\mathrm{de}}$ & $6,25^{\mathrm{bcd}}$ & $12,01^{\mathrm{f}}$ \\
$3 \%$ & $7,28^{\mathrm{cd}}$ & $12,62^{\mathrm{f}}$ & $5,98^{\mathrm{bcd}}$ \\
$4 \%$ & $3,76^{\mathrm{ab}}$ & $6,79^{\mathrm{cd}}$ & $10,74^{\mathrm{ef}}$ \\
\hline
\end{tabular}

Berdasarkan Tabel 2 terlihat bahwa perlakuan suhu dan kitosan mempengaruhi kadar klorofil total kulit buah srikaya. Perlakuan yang paling baik mempertahankan klorofil kulit buah srikaya ditunjukkan dengan tingginya nilai kadar klorofil adalah perlakuan kitosan $3 \%$ dan penyimpanan $15^{\circ} \mathrm{C}$ yaitu sebesar $12,62 \mathrm{mg} / \mathrm{l}$. Adapun data karotenoid dapat dilihat pada Tabel 3. 
Tabel 3. Karotenoid buah srikaya pada variasi konsentrasi kitosan dan penyimpanan suhu $(\mathrm{mg} / \mathrm{l})$.

\begin{tabular}{ccll}
\hline Kitosan & $5^{\circ} \mathrm{C}$ & $15^{\circ} \mathrm{C}$ & $25^{\circ} \mathrm{C}$ \\
\hline $0 \%$ & $1,11^{\mathrm{abc}}$ & $1,69^{\mathrm{bcd}}$ & $3,28^{\mathrm{ef}}$ \\
$2 \%$ & $1,95^{\mathrm{cd}}$ & $1,47^{\mathrm{bcd}}$ & $3,40^{\mathrm{f}}$ \\
$3 \%$ & $1,75^{\mathrm{ab}}$ & $0,40^{\mathrm{a}}$ & $0,99^{\mathrm{ab}}$ \\
$4 \%$ & $0,94^{\mathrm{ab}}$ & $1,60^{\mathrm{bcd}}$ & $2,49^{\mathrm{de}}$ \\
\hline
\end{tabular}

Hasil penelitian menunjukkan bahwa perlakuan suhu dan kitosan mempengaruhi kadar karotenoid kulit buah srikaya. Perlakuan pelapisan kitosan $3 \%$ dan suhu $15^{\circ} \mathrm{C}$ menunjukkan kadar karotenoid yang paling rendah. Jika dilihat dari Tabel 2 dan 3 maka kombinasi perlakuan ini paling baik mempertahankan warna kulit buah srikaya karena karotenoidnya rendah dan klorofilnya tinggi.

Pantastico (1986), menyatakan bahwa kandungan klorofil buah yang sedang masak lambat laun berkurang. Berkurangnya kandungan klorofil disebabkan oleh meningkatnya aktivitas enzim klorofilase yang fungsinya mendegradasi klorofil. Hasil dari degradasi klorofil digunakan sebagai bahan sintesa dalam pembuatan etilen pada buahbuahan (Winarno dan Aman, 1981). Hilangnya warna hijau pada buah mungkin karena terjadi oksidasi atau penjenuhan terhadap ikatan rangkap molekul klorofil (Muchtadi dan Sugiyono, 1992).

Perubahan warna adalah perubahan yang paling menonjol pada waktu pematangan, terjadi sintesa pigmen tertentu, seperti karotenoid dan flavonoid di samping terjadi perombakan klorofil (Apandi, 1984). Warna buah masak disebabkan oleh sintesis karotenoid dan antosianin. Pada periode matang ditandai dengan terjadinya reduksi karoten. Untuk kebanyakan buah, tanda kematangan pertama adalah hilangnya warna hijau. Kandungan klorofil buah yang sedang masak lambat laun berkurang, pada umumnya sejumlah zat warna hijau tetap terdapat dalam buah, terutama dalam jaringan bagian-bagian dalam buah (Jayaputra dan Nurrachman, 2005).

\section{Kadar vitamin $\mathrm{C}$}

Vitamin C merupakan senyawa yang dekat dengan struktur monosakarida, secara formal diturunkan dari L-glukosa, suatu aldoheksosa. Senyawa ini dapat terbentuk sebagai asam Laskorbat dan asam L-dehidroaskorbat, keduanya mempunyai kereaktifan sebagai vitamin C (Caultate, 1980). Apandi (1984) menyatakan bahwa asam askorbat atau vitamin $\mathrm{C}$ dapat disintesis dari glukosa yang terkandung pada buahbuahan. Selama pematangan buah terjadi peningkatan kimiawi sebagai aktivitas beberapa enzim antara lain kegiatan peroksidase yang mempercepat pemasakan buah, kegiatan enzim amilase dalam mengubah zat pati menjadi maltosa lalu maltosa akan diubah oleh enzim maltase menjadi glukosa. Selanjutnya glukosa, fruktosa, sukrosa, dan D-galaktosa yang ada dalam jaringan akan diubah menjadi vitamin $\mathrm{C}$.

Berdasarkan hasil penelitian (Tabel 4) terlihat bahwa perlakuan suhu dan kitosan mampu mempengaruhi kadar vitamin $\mathrm{C}$ buah srikaya. Semakin tinggi suhu, kadar vitamin $\mathrm{C}$ buah srikaya juga semakin tinggi. Hal ini menunjukkan bahwa suhu rendah mampu menghambat proses pembentukan vitamin $\mathrm{C}$ buah. Pelapisan kitosan dan suhu rendah menghambat masuknya gas antara lain oksigen sehingga respirasi dan metabolisme pembentukan vitamin $\mathrm{C}$ terhambat. Kadar vitamin $\mathrm{C}$ terendah pada perlakuan pelapisan kitosan $2 \%$ kemudian $3 \%$ pada suhu $15{ }^{\circ} \mathrm{C}$. Adapun data vitamin $\mathrm{C}$ dapat dilihat pada Tabel 4 berikut,

Tabel 4. Vitamin $C$ buah srikaya pada variasi konsentrasi kitosan dan suhu penyimpanan $(\mathrm{mg} / 100 \mathrm{~g})$.

\begin{tabular}{clcc}
\hline Suhu & $5{ }^{\circ} \mathrm{C}$ & $15^{\circ} \mathrm{C}$ & $25^{\circ} \mathrm{C}$ \\
\hline $0 \%$ & $26,62^{\mathrm{a}}$ & $19,13^{\mathrm{a}}$ & $76,60^{\mathrm{bc}}$ \\
$2 \%$ & $20,41^{\mathrm{a}}$ & $13,62^{\mathrm{a}}$ & $96,31^{\mathrm{c}}$ \\
$3 \%$ & $36,54^{\mathrm{a}}$ & $20,35^{\mathrm{a}}$ & $141,83^{\mathrm{d}}$ \\
$4 \%$ & $29,71^{\mathrm{a}}$ & $29,35^{\mathrm{a}}$ & $71,02^{\mathrm{d}}$ \\
\hline
\end{tabular}

Pelapisan buah dengan kitosan berbagai konsentrasi menyebabkan pori-pori permukaan kulit buah tertutup sehingga masuk dan keluarnya gas menjadi terhambat akibatnya proses respirasi dan oksidasi yang terjadi pada vitamin $\mathrm{C}$ dapat dihambat. Apabila sel mengalami kelayuan, enzim askorbat oksidase akan dibebaskan dengan cara kontak langsung dengan asam askorbat sehingga vitamin C mengalami kerusakan (Gaman dan Serington, 1992).

\section{Respirasi}

Proses respirasi dimulai dengan proses perombakan pati. Sebagian besar langkah dalam proses 
perombakan pati menjadi glukosa dikatalis oleh tiga macam enzim yaitu $\alpha$-amilase, $\beta$-amilase, dan pati fosforilase. Dari ketiganya, hanya $\alpha$-amilase yang dapat menyerang butir pati utuh, sehingga bila $\beta$-amilase dan pati fosforilase terlibat. Data respirasi dapat dilihat pada Gambar 1 dan 2.

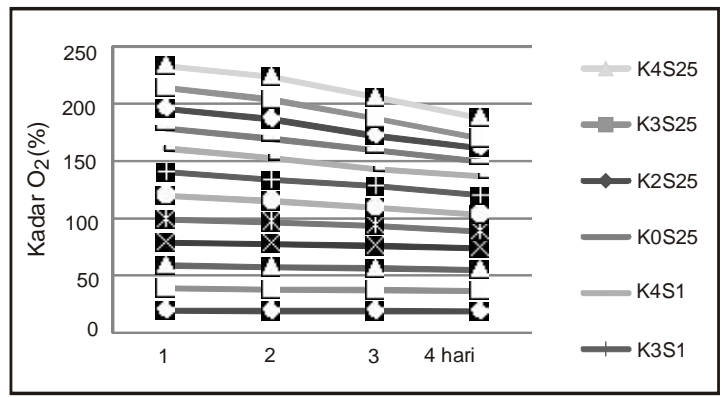

Gambar 1. Kadar $\mathrm{O}_{2}$ srikaya selama 4 hari setelah perlakuan pelapisan kitosan dan suhu rendah $(\%)$.

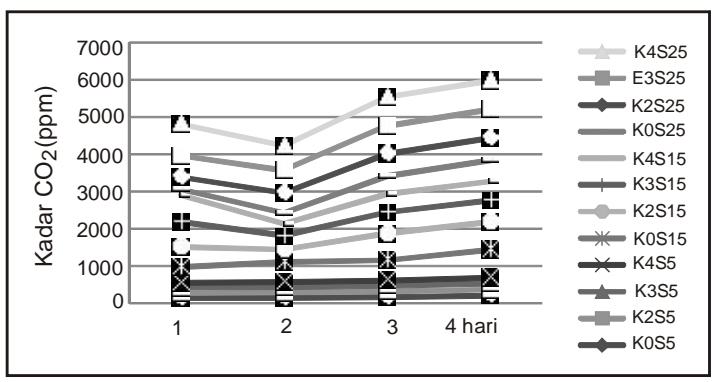

Gambar 2. Kadar $\mathrm{CO}_{2}$ srikaya selama 4 hari setelah perlakuan pelapisan kitosan dan suhu rendah (ppm).

Berdasarkan hasil penelitian terlihat bahwa pada hari ke 4 buah srikaya sudah masak. Terjadi penurunan kadar $\mathrm{O}_{2}$ selama 4 hari. Hal ini disebabkan karena oksigen digunakan untuk respirasi aerob buah selama proses pematangan. Kebalikannya, $\mathrm{CO}_{2}$ semakin meningkat selama 4 hari sebagai gas hasil respirasi. Semakin rendah suhu, $\mathrm{O}_{2}$ yang digunakan untuk respirasi semakin sedikit. Suhu $5^{\circ} \mathrm{C}$ paling efektif menurunkan respirasi.

Glikolisis merupakan tahap pertama dari tiga fase respirasi yang sangat berkaitan, diikuti oleh daur krebs dan pengangkutan elektron yang terjadi di mitokondria. Istilah glikolisis yang berarti pemecahan gula diperkenalkan pada tahun 1909 untuk maksud perombakan gula menjadi etil alkohol (etanol). Sebagian besar akan menghasilkan asam ipiruvat, bukan etanol, jika mendapat aerasi secara normal. Gula yang lazim dirombak adalah heksosa, sehingga glokolisis berarti perombakan heksosa menjadi asam piruvat. Pada tahap ini dihasilkan 2 molekul NADH serta 2 molekul ATP (Salisbury dan Ross, 1995).

Daur Krebs dimulai dengan proses kondensasi asetil CoA dengan asam oksaloasetat membentuk asam sitrat dengan bantuan enzim sitrat sintase. Selanjutnya terjadi proses dehidrasi dan hidratasi asam sitrat membentuk asam isositrat yang melibatkan enzim akonitase. Asam isositrat yang dihasilkan diubah menjadi $\alpha$-ketoglutarat oleh enzim isositrat dehidrogenase melalui proses oksidasi dan dekarboksilasi. Terjadi proses oksidasi, dekarboksilasi, hidrolisis, dan sintesis ATP senyawa dari asam $\alpha$-ketoglutarat menjadi asam suksinat dengan bantuan enzim $\alpha$-ketoglutarat dehidrogenase (oksidasi dan dekarboksilasi) dan suksinil CoA sintetase (hidrolisis dan sintesis ATP). Asam suksinat diubah menjadi asam fumarat oleh enzim suksinat dehidrogenase melalui proses oksidasi. Asam fumarat melalui proses hidratasi diubah menjadi asam malat oleh enzim fumarase, dan yang terakhir adalah proses oksidasi asam malat menjadi asam oksaloasetat dengan bantuan enzim malat dehidrogenase (Salisbury dan Ross, 1995).

Proses respirasi yang terjadi pada buah dilakukan melalui permukaan kulit buah. Pelapisan kitosan pada berbagai konsentrasi menyebabkan tertutupnya pori-pori permukaan kulit buah sehingga aktivitas respirasi dan traspirasi pada buah dapat terhambat atau berkurang (Santosa, 2011).

\section{Gula reduksi ini}

Flavor adalah sesuatu yang halus dan rumit yang ditangkap indera, yang merupakan kombinasi rasa (manis, asam, sepet) bau (zat-zat atsiri), dan terasanya pada lidah (meleleh, pedas) Pematangan biasa meningkatkan jumlah gula-gula sederhana yang memberi rasa manis, penurunan asam-asam organik dan senyawa-senyawa fenolik yang mengurangi rasa sepet dan masam, dan kenaikan zat-zat atsiri yang memberi flavor khas pada buah.

Data gula reduksi pada srikaya yang telah dilapisi kitosan dan disimpan dalam suhu rendah disajikan pada tabel 5 . 
Tabel 5. Total gula reduksi buah Srikaya pada variasi konsentrasi kitosan dan penyimpanan suhu (mg/100g).

\begin{tabular}{|c|c|c|c|}
\hline Kitosan & $5^{\circ} \mathrm{C}$ & $15^{0} \mathrm{C}$ & $25{ }^{0} \mathrm{C}$ \\
\hline $0 \%$ & $17,07^{\mathrm{a}}$ & $20,16^{a}$ & $52,88^{\mathrm{c}}$ \\
\hline $2 \%$ & $26,76^{a b}$ & $28,23^{\mathrm{ab}}$ & $51,29^{\mathrm{c}}$ \\
\hline $3 \%$ & $27,15^{a b}$ & $23,16^{\mathrm{ab}}$ & $53,10^{\mathrm{c}}$ \\
\hline $4 \%$ & $27,09^{a b}$ & $31,90^{b}$ & $47,69^{\mathrm{c}}$ \\
\hline
\end{tabular}

Perlakuan suhu rendah dan pelapisan kitosan mampu menghambat pembentukan gula reduksi. Hal ini ditunjukkan dengan tingginya kadar gula reduksi pada kontrol dibandingkan perlakuan lain. Suhu $5^{\circ} \mathrm{C}$ paling efektif menurunkan kadar gula reduksi. Semakin tinggi suhu, kadar gula reduksi semakin meningkat. Efek suhu lebih signifikan menurunkan kadar gula reduksi dibandingkan pelapisan kitosan. Perlakuan terbaik yang menurunkan kadar gula reduksi adalah pada suhu $5^{\circ} \mathrm{C}$ dan kitosan $0 \%$, kemudian suhu $15^{\circ} \mathrm{C}$ dan kitosan $0 \%$ serta suhu $15^{\circ} \mathrm{C}$ dan kitosan $3 \%$.

\section{Kekerasan buah}

Lunaknya buah disebabkan oleh perombakan protopektin yang tak larut menjadi pektin yang larut atau hidrolisis zat pati (seperti pada waluh) atau lemak (seperti pada alpukat.) Sintesis zat kayu pada beberapa sayuran yang berupa buah dapat pula berpengaruh buruk terhadap tekstur.

Data mengenai kekerasan buah srikaya dapat dilihat pada Tabel 6 dan 7 .

Tabel 6.Tekstur sisik kulit buah srikaya pada variasi konsentrasi kitosan dan suhu penyimpanan $(\mathrm{kg})$.

\begin{tabular}{cccc}
\hline Kitosan & $5{ }^{\circ} \mathrm{C}$ & $15^{\circ} \mathrm{C}$ & $25^{\circ} \mathrm{C}$ \\
\hline $0 \%$ & $0,16^{\mathrm{a}}$ & $0,21^{\mathrm{b}}$ & $0,31^{\mathrm{c}}$ \\
$2 \%$ & $0,22^{\mathrm{b}}$ & $0,32^{\mathrm{c}}$ & $0,35^{\mathrm{d}}$ \\
$3 \%$ & $0,24^{\mathrm{b}}$ & $0,30^{\mathrm{c}}$ & $0,35^{\mathrm{d}}$ \\
$4 \%$ & $0,17^{\mathrm{a}}$ & $0,30^{\mathrm{c}}$ & $0,22^{\mathrm{b}}$ \\
\hline
\end{tabular}

Tabel 7.Tekstur celah kulit buah srikaya pada variasi konsentrasi kitosan dan suhu penyimpanan $(\mathrm{kg})$.

\begin{tabular}{|c|c|c|c|}
\hline Kitosan & $5^{0} \mathrm{C}$ & $15^{0} \mathrm{C}$ & $25^{0} \mathrm{C}$ \\
\hline $0 \%$ & $0,13^{\mathrm{a}}$ & $0,30^{d}$ & $0,21^{b}$ \\
\hline $2 \%$ & $0,15^{\mathrm{a}}$ & $0,27^{\mathrm{c}}$ & $0,20^{b}$ \\
\hline $3 \%$ & $0,26^{\mathrm{c}}$ & $0,28^{\mathrm{cd}}$ & $0,22^{b}$ \\
\hline $4 \%$ & $0,31^{\mathrm{d}}$ & $0,27^{\mathrm{c}}$ & $0,20^{\mathrm{b}}$ \\
\hline
\end{tabular}

Hasil penelitian menunjukkan bahwa sisik kulit mempunyai kekerasan yang lebih tinggi dari pada celah kulit srikaya. Semakin buah matang, kekerasan semakin rendah. Perlakuan pada suhu rendah mempunyai kulit dan celah yang lebih keras daripada kontrol (suhu $25^{\circ} \mathrm{C}$ pelapisan $0 \%$ ). Pelapisan kitosan juga mampu mencegah gas masuk ke dalam celah kulit srikaya, sehingga respirasi terhambat. Hasil penelitian menunjukkan bahwa pelapisan kitosan yang semakin pekat atau tinggi menyebabkan terhambatnya proses pelunakan daging buah Srikaya. Suhu rendah juga mampu mempertahankan kulit buah tetap keras.

\section{Kadar etilen}

Hasil penelitian menunjukkan bahwa pada suhu $25^{\circ} \mathrm{C}$ kadar etilen lebih tinggi daripada suhu rendah. Data yang berlambang - menunjukkan etilen tidak mampu terdeteksi kromatografi gas karena kadarnya terlalu rendah. Semakin tinggi kadar kitosan, semakin rendah kadar etilennya.

Kadar etilen pada berbagai perlakuan dapat dilihat pada Tabel 8.

Tabel 8. Kadar etilen buah srikaya pada variasi konsentrasi kitosan dan suhu penyimpanan (ppm).

\begin{tabular}{cccc}
\hline Kitosan & $5{ }^{0} \mathrm{C}$ & $15{ }^{\circ} \mathrm{C}$ & $25{ }^{0} \mathrm{C}$ \\
\hline $0 \%$ & 83 & - & - \\
$2 \%$ & 57 & 37 & 21 \\
$3 \%$ & 34 & 24 & 8 \\
$4 \%$ & - & - & - \\
\hline
\end{tabular}

Etilen adalah zat yang secara alami berperan sangat penting pada proses fisiologi pascapanen, diantaranya mempercepat senesen dan menurunkan umur simpan, memicu respirasi klimakterik, mempercepat dan menyeragamkan pemasakan (Kader, 1985; Kays, 1997). Etilen mengatur pemasakan buah dengan mengkoordinasikan ekspresi gen-gen yang bertanggung jawab dalam berbagai proses termasuk peningkatan laju respirasi, autokatalitik produksi etilen, degradasi klorofil, sintesis karotenoid, konversi pati menjadi gula, dan peningkatan aktivitas enzim-enzim pemecah dinding sel (Winarno, 1992).

\section{KESIMPULAN}

1. Kombinasi perlakuan konsentrasi kitosan dan variasi suhu penyimpanan menunjukkan pengaruh yang berbeda nyata terhadap masa simpan buah srikaya yang diukur dari beberapa parameter. Perlakuan tersebut mampu me- 
ngurangi susut berat buah, mempertahankan kadar air buah tetap tinggi, mempertahankan kadar total gula reduksi tetap tinggi, mempertahankan kadar vitamin C tetap tinggi, menurunkan laju respirasi, mempertahankan kadar klorofil a, klorofil b, klorofil total, dan karotenoid tetap tinggi.

2. Kombinasi perlakuan konsentrasi kitosan dan variasi suhu penyimpanan yang paling lama dalam memperpanjang masa simpan buah srikaya adalah kitosan $3 \%$ pada suhu $15^{\circ} \mathrm{C}$.

\section{DAFTAR PUSTAKA}

Apandi, M. 1984. Teknologi Buah dan Sayur. IPB Pess, Bandung.

Burdon, J.N. 1997. Postharvest Handling of Tropical and Subtropical Fruit for Eksport. Dalam: S. Mitra (Ed.) Postharvest Physiology and Storage of Tropical and Subtropical Fruits. CAB International, London.

Caultate, T.P. 1980. Food the Chemistry of Its Component Edisi ke-2. The Royal Society of Chemistry, Cambrige USA.

Gaman, P.M. dan K.B. Sherrington. 1992. Ilmu Pangan, Pengantar Ilmu Pangan, Nutrisi, dan Mikrobiologi. Universitas Gajah Mada, Yogyakarta.

Jayaputra dan Nurrachman. 2005. Kajian Sumber Khitosan sebagai Bahan Pelapis, Pengaruhnya terhadap Masa Simpan dan Karakteristik Buah Mangga Selama Penyimpanan. Naskah Penelitian. Program Studi Hortikultura Fakultas Pertanian Universitas Mataram, Mataram.
Kays, S. 1991. Postharvest Physiology of Perishable Plant Product. AVI Book, New York.

Muchtadi, T. R. dan Sugiyono. 1992. Ilmu Pengetahuan Bahan Pangan. PAU Pangan dan Gizi Institut Pertanian Bogor, Bogor.

Pantastico, E.B. 1986. Fisiologi Pasca Panen, Penanganan, dan Pemanfaatan Buahbuahan dan Sayuran-sayuran Tropika dan Subtropika. Gadjah Mada University Press, Yogyakarta.

Salisbury, F. dan C. Ross. 1995. Terjemahan Diah R. Lukman dan Sumaryono dari Plant Physiology. $4^{\text {th }}$ Edition. Institute Teknologi Bandung, Bandung.

Santoso, B.B. 2011. Fisiologi dan Biokimia pada Komoditi Panenan Hortikultura. Fakultas Pertanian, Universitas Mataram, Mataram.

Wills, R.H., T.H.Lee, D. Graham, W.B. McKasson, and E.G. Hall. 1981. Postharvest, an Introduction to the Physiology and Handling of Fruits and Vegetables. New South Wales University Press, Kensington Australia.

Winarno, F.G. 1992. Kimia Pangan dan Gizi. Gramedia, Jakarta.

Winarno, F.G. dan M. Aman. 1981. Fisiologi Lepas Panen. PT. Sastra Hudaya, Jakarta. 